\title{
Pequeña lámpara gemela: mapa esquivo del ars poetica femenina en Venezuela
}

\author{
Quién sabe si labraremos -fecunda acción-lo salvaje. \\ Enriqueta Arvelo Larriva, Voz aislada
}

\section{Primer esbozo «in media res»}

Este trabajo se propone realizar un recorrido histórico por la poesía femenina en Venezuela a partir de un elemento central que la constituye: la reflexión sobre la poesía misma, es decir, la meditación sobre sus formas, técnicas y funciones, con el fin de visibilizar y comprender una tradición de pensamiento crítico y autorreflexivo pocas veces atribuido a la producción poética femenina por el imaginario androcéntrico.

Decimos «pocas veces» porque el discurso crítico tradicional ha subrayado la falta de abstracción en la poesía femenina, destacando su sentimentalismo o extremo erotismo, su reclusión en temas domésticos y familiares, y sobre todo la ausencia de perspectivas simbólicas o intelectuales de amplio alcance. La crítica feminista latinoamericana ha entregado ya contundentes respuestas en relación a estos prejuicios, apuntando a diferentes direcciones. Basta mencionar apenas dos de ellas, porque constituyen campos de investigación abiertos a la interpretación literaria y cultural de autoría femenina con perspectiva crítica renovada e independiente. En efecto, si un campo reconfirma el prejuicio subvirtiendo su sentido, otro campo de la crítica se ocupa en deconstruir las complejidades discursivas borradas $\mathrm{u}$ omitidas.

Así lo muestra, en el primer caso, un temprano artículo de Marta Traba de 1981 valorando dicha subversión y entendiéndola como una fuerza por explotar:

Tengo la impresión que la literatura femenina, paternalmente admitida como una expresión menor desde las pautas de valor formuladas por los hombres, en cambio de disimular su condición, tratando de desprenderse de sus adherencias con la realidad y alcanzar un buen nivel de abstracciones simbólicas, podría constituirse en un fuerte mediador, si aceptara y explotara su especificidad. ${ }^{1}$

1 Marta Traba: «La literatura femenina». El Universal (25 de enero de 1981). Caracas, p. 15.

Márgara Russotto, University of Massachusetts/Amherst

Ә Open Access. (c) 2021 Márgara Russotto, published by De Gruyter. (@) BY-NC-ND This work is licensed under the Creative Commons Attribution-NonCommercial-NoDerivatives 4.0 International License. 
Igualmente subversivo fue, en el segundo campo o línea de investigación, el fino bisturí analítico de Josefina Ludmer en su ensayo «Tretas del débil», donde explora el intrincado tejido entre el silencio y la palabra de sor Juana en su famosa Respuesta a sor Filotea. Importa remitirse a estos estudios, aunque sea como pro-memoria o beneficio de inventario y a pesar de ser ampliamente «superados» por los cambios históricos, porque ellos marcaron un reajuste radical en el horizonte de la recepción crítica de la literatura de autoría femenina. Reunidos en el conocido volumen La sartén por el mango (1984), sus reflexiones siguen proyectándose sobre el presente como parte de una historia inacabada y un proceso de creación independiente que tuvieron, en la Venezuela del siglo XX, una importancia capital, especialmente para las escritoras.

La Respuesta a sor Filotea de sor Juana, en particular, constituye un modelo de pensar y poetizar emblemático para las escritoras, cuyo reconocimiento vinculante podría trazar un primer bosquejo del supuesto mapa que nos ocupa. Como muestra el estudio de Ludmer, sor Juana comete la osadía de exponer al sujeto femenino como sujeto de la escritura mediante un juego sutil de luces y sombras sobre su vida y su pensamiento, desarrollando las estrategias discursivas de auto-preservación y camuflaje, indispensables en el contexto autoritario y ultra burocrático de la inquisición en el México del siglo XVII. Estrategias estas que seguirán siendo practicadas en gran parte por la autoría femenina en épocas menos remotas.

Maestra en el ejercicio crítico y el control del discurso desde una clara posición de género, la obra de sor Juana constituye una suerte de hipotexto universal que funda la genealogía poética femenina latinoamericana tanto en la simulación como en la subversión. Su ejemplaridad ha sido un factor de convergencia e inspiración, no solo confirmada por una serie de importantes investigaciones de diferentes épocas y tendencias, sino porque su legado ilustrado y libertario ha sido incorporado por nuestras poetas en innumerables modos y ejemplos, desde la referencia en un simple verso a largas creaciones de complicada intertextualidad.

\section{Una poética civilizatoria}

La obra poética de Luz Machado (1916-1999) puede ilustrar el alcance de dicho legado, no solamente en sus 24 Sonetos a la sombra de sor Juana Inés de la Cruz (1966) donde desarrolla el tópico del amor no correspondido, sino en la incorporación transversal del imaginario sorjuanino sobre las diferencias entre la apariencia y la verdad. Si sor Juana hizo del soneto a su retrato, «Este que ves, engaño colorido» (Soneto 145), la prueba del mundo como ilusión y su disyunción 
respecto al arte, el poema de Luz Machado, «Miro la casa desde un retrato», repotencia el desdoblamiento, cambia el punto de observación (ya que habla «desde» el retrato y también desde su contemplación exterior), y acaba con la distancia entre sujeto del enunciado y sujeto de la enunciación adelantando una doble crítica a la representación misma: la del retrato y la del poema que pretende describirlo. He aquí un fragmento del poema que forma parte del libro La casa por dentro (1965):

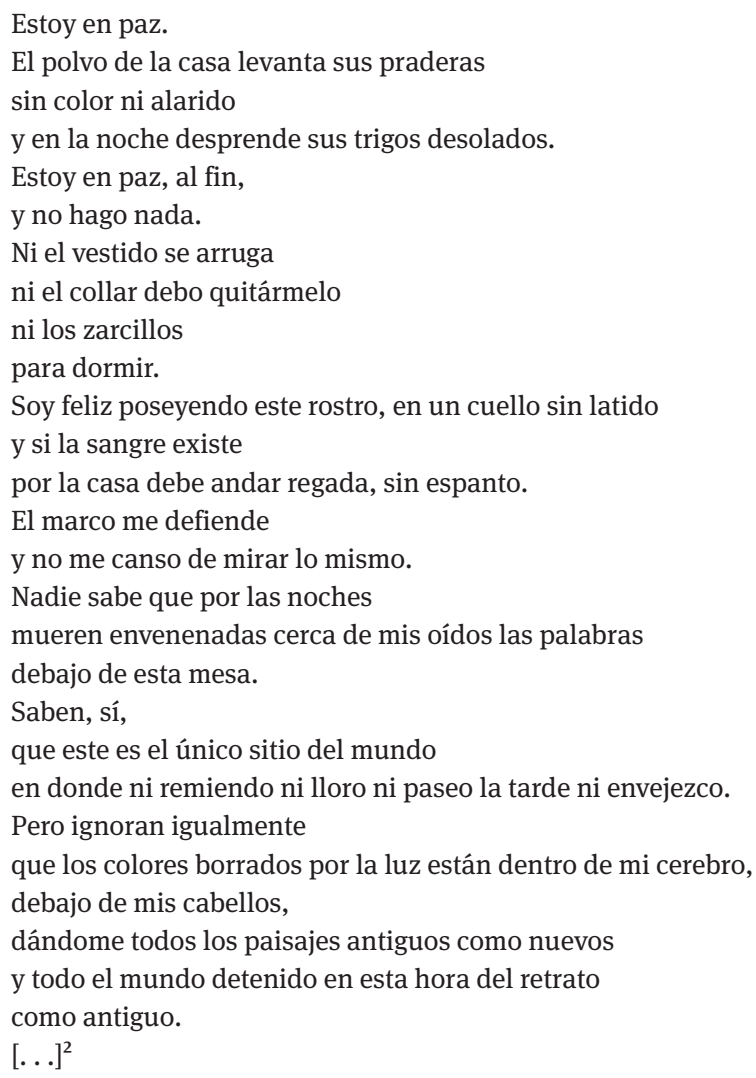

El artificio del retrato suspende el tiempo, la vejez, las quejas, escondiendo el dolor real -y sus palabras- «debajo de esta mesa», que es la mesa de la escritura. Naturalmente, no es el espíritu barroco con sus disimulos y artificios lo que sobresale. Los versos libres de corte narrativo y coloquial retoman, sí, el tema de la apariencia, pero sin contorsiones ni efectismos, para mostrar la dimensión

2 Luz Machado: La casa por dentro (1964-1965). Caracas: Sucre 1965, p. 21. 
existencial de cada objeto desde un punto de observación que intenta ser neutral, o neutralizado por una perspectiva crítica y auto-reflexiva.

Luz Machado rompe la opacidad objetual, como si le diera voz a las cosas en busca de su profundidad específica y simbólica, pues el sujeto lírico está inmerso en un mundo cerrado y no obstante plural, en actitud vigilante de intensa observación, y observándose. De igual manera, el breve poema «El ajo» - ese modestísimo ingrediente de todas las cocinas- expresa las tensiones entre lo singular y lo plural, y a la vez la identidad completa y autosuficiente de cada pequeño gajo:

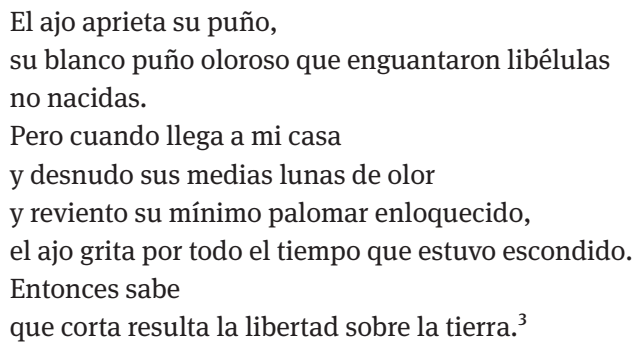

El ajo es para Luz Machado - como la tortilla para sor Juana y el huevo para Clarice Lispector ${ }^{4}$ - la perfecta «adherencia con la realidad» de su tiempo y su género, libre de disimulos y a la vez potenciada hasta insospechados vuelos filosóficos. Y es mucho más, ya que dichas adherencias no pueden ser entendidas como simples envoltorios materiales de rústica imitación gracias a la potestad de transformarse en algo totalmente diferente. Tal vez la compacta identidad del ajo que se despliega en un grito de libertad quiera decirnos que el conocimiento del mundo solo es posible disolviendo su opacidad mediante un proceso analítico disruptivo; es decir, mediante el ejercicio de la poesía crítica de la cual el poema mismo constituye un momento decisivo.

Toda la obra de esta escritora, poeta, periodista y diplomática venezolana, es una intensa discusión sobre la poesía, el poema, y la figuración, entre clásica y romántica, del poeta mismo, el cual es representado como un adolescente delicado y solitario en su función de iluminar y sostener el peso de la vida. Hay una mirada de humildad sobre el mundo desde estos escenarios de la intimidad, y una

\footnotetext{
3 Ibid., p. 70.

4 Nos referimos a la conocida Respuesta de sor Juana ya mencionada y analizada por Ludmer. Igualmente, recordamos el cuento «El huevo y la gallina», de Clarice Lispector, donde la acción y desarrollo del relato se basan en las especulaciones filosóficas de una mujer friendo los huevos para el desayuno familiar, hasta el punto de convertir el huevo en la gran metáfora de las contradicciones sociales y de complicadas epistemologías, poniendo en jaque la validez del conocimiento.
} 
revelación del sujeto lírico en actitud compasiva. Como evidencian estos versos de «El poema», la figura del poeta surge «con sus zapatos rotos y suavísimos, / con el rostro caído ante la luz y el color, / mirando fijamente las imágenes desde su melancolía [. . . ] como si colocara un par de alas / para un sueño y un viaje, reunidos / en el desconocimiento». ${ }^{5}$ La función sigilosa de la poesía consiste entonces en aligerar también el lenguaje de todo su peso y artificio, como un rayo de luz sobre las cosas cuya delicadeza reduce el dolor del vivir entre humanas privaciones. Pero es también una secreta compañía, una pobreza que ennoblece y trae luz desde su «suave cabellera constelada». Es, definitivamente, luz: «porque yo te conozco y me conoces, / oh, mi pequeña lámpara gemela, poesía, / ante quien solamente me arrodillo, / pecadora». («Ruego a la poesía»). ${ }^{6}$

Hay aquí aguda consciencia sobre el extenso tejido de relaciones y responsabilidades entre la poesía como entelequia, el poema como objeto imperfecto de traducción, y el sujeto lírico que ora se identifica con la grandeza del ideal, ora con sus propios límites tanto compositivos como existenciales. Y ora es poesía, ora es poema. Ora es el Ama que gobierna el orden universal, ora es quien lo padece. En estos dialogismos puede percibirse las «huellas» de lo biográfico; las «marcas» epocales de lo privado y de los orígenes de la convivencia con el otro, que es íntima en los afectos, y social en sus complejas conexiones con el mundo, problematizando así la identidad misma del sujeto lírico «en su ir y venir desde lo empírico hacia lo trascendente», ${ }^{7}$ de la experiencia autobiográfica a la experiencia universal soñada que solo se vislumbra en la ficción.

En la obra de Luz Machado, numerosos poemas, poemarios completos, cartas y dedicatorias «a la poesía», tienen un contenido crítico que relativiza la separación entre sujeto empírico y sujeto lírico, interponiendo el proceso de un sujeto retórico o figural que los separa y vincula al mismo tiempo. En particular, los poemas incluidos en el volumen mencionado - cuyo sentido a menudo ha sido reducido y simplificado por la literalidad del título- constituyen en su conjunto no solo el despliegue de una perspectiva crítica sino también la visión totalizante de una poética, en todos sus fundamentos y simbolizaciones. En el poema que lleva el mismo título del libro, se dice:

La casa necesita mis dos manos.

Yo debo sostener su cal como mis huesos, su sal como mis gozos,

5 Luz Machado: La casa, p. 17.

6 Ibid., p. 61.

7 Dominique Combe: «A referência desdobrada: O sujeito lírico entre a ficçao e a autobigrafia». In: Revista USP 84 (2010), p. 51. 
su fábula en la noche

y el sol ardiendo en mitad de su cuerpo.

[...]

Debo atender su réplica del universo,

la memoria del campo en los floreros,

la unánime vigilia de la mesa,

la almohada y su igualdad de pájaros dispersos,

(...)

Debo quererla entera, salida de mis manos

con la gracia que vive de mi gracia muriendo.

$[\ldots]^{8}$

Lejos de tratarse del espacio de una domesticidad obligante, pasiva o degradante, el domus es el marco que encierra un universo de rica multiplicidad simbólica, el asiento de las primeras experiencias formativas y la posibilidad misma de construir, ladrillo por ladrillo, una poética total. Observada en su intimidad espacial y material, la casa surge como la macro metáfora estructuradora de una poética de la vida civil, civilizadora, a partir del cuidado y la preservación que afecta desde las relaciones familiares al ocio, la educación de los niños, el amor y el deseo de otros mundos, la libertad y el precio de su renunciación que puede llevar a la muerte del mismo sujeto lírico. En esa primera convivencia con la alteridad fijada a través de los objetos materiales, todo se convierte en instrumento de la poesía: cortinas, lámparas, puertas, cumpleaños, anillos de boda, zapatos, alfombras... De modo que hasta la observación de un objeto tan trivial como un cenicero recupera las raíces culturales de una región productora de tabaco, con sus largas hojas vegetales y un tiempo de aparición mágica en la memoria. Y no parece menos noble o significativa la ceniza como medio para la recordación, frente a la proustiana madeleine en el té. Todo lo contrario.

La construcción de esta casa/poética, entonces, debe hacerse «con las dos manos», porque el sentimiento y la razón, como también la forma y la función, deben ir juntos, integrando ética y estética según el ideal clásico, tal como sostenía Horacio en su Epístola a los Pisones.

Que en el suelo bárbaro y violento del medio siglo venezolano se diera una poética de aspiración clásica invitando a una visión general del arte y la belleza igualmente ética y no solamente estética, no es poco decir. Lejos de ser un anacronismo de romanticismo tardío, o incluso siéndolo en clave perturbadora y subvertida, se trata de un proyecto más amplio de formación y conocimiento, de alusiones a un mundo en parte ajeno a la experiencia y la mentalidad masculinas

8 Luz Machado: La casa, p. 9. 
de la época, ensimismado en las visiones del poeta maldito que dominó gran parte del siglo XX venezolano.

Por estas razones creemos que se justifica iniciar este supuesto diseño cartográfico entrando «in media res» con la poética machadiana, no solo porque retoma el hilo de la genealogía sorjuanina sino porque podría entenderse también como una «vuelta al orden», o una llamada indirecta para ir a las raíces del «desorden».

\section{Itinerario a grandes saltos}

Pero volvamos al principio tratando de desplegar el imposible mapa. El primer momento significativo de la modernidad en la poesía venezolana de autoría femenina se gesta en el silencio. Son las primeras décadas del siglo XX, un tiempo en que la posición marginal o transversal de las mujeres en la historia literaria, con sus excepciones y desvíos en relación a las tendencias dominantes, dificultó cualquier intento de periodización estable y de registro canónico. Como ellas mismas revelan en numerosas entrevistas y textos autobiográficos, las poetas se han «labrado en soledad», a la retaguardia de una vanguardia hecha de saltos e interrupciones. Salvo pocos casos, ellas fueron figuras marginales entre los grupos literarios, independientemente del reconocimiento de su trayectoria como escritoras. Aun suscribiendo algunos manifiestos, se mantuvieron al margen de los debates estéticos e ideológicos, y de los conflictos y proclamas que protagonizaron el flujo y reflujo de los brotes modernizadores de la sociedad venezolana.

Este aislamiento es especialmente dramático durante las primeras décadas del siglo y hasta el fin de la dictadura de Juan Vicente Gómez en diciembre de 1935, y es vivido a conciencia por Enriqueta Arvelo Larriva (1886-1962), cuyo primer poemario lleva justamente el título de Voz aislada (1939). Enriqueta vive y escribe desde Barinitas, un pueblito al pie de los Andes en el inmenso llano venezolano, donde cumple mil oficios «civilizadores» según las necesidades de la provincia, desde enfermera a escribana y maestra rural. Igualmente civilizadores serán sus artículos culturales en el diario El Nacional, donde utiliza el pseudónimo «Santica Luzardo», en honor a Santos Luzardo, héroe de la novela Doña Bárbara (1929) de Rómulo Gallegos (1884-1969) y personaje emblemático en la lucha de la civilización contra la barbarie.

Sus versos comunican sin embargo la extrañeza y el gozo de una libertad sin normas ni guía; un ritmo y un vocabulario nuevo que no es nativista ni modernista, ni clásico ni romántico, desde un ámbito de aridez geopolítica, climática y cultural. Desde allí, desde la provincia al margen de la marginalidad, emana su 
lenguaje original: «Toda la mañana ha hablado el viento / una lengua extraordinaria», dice. Y poco importa sembrar la voz «en el montón sordo», esbozar «signos que gritan en vano», o andar «por caminos que no me oían». ${ }^{9}$

Aridez y aislamiento social, orgullosa invisibilidad y espíritu bravío impactan con su autenticidad en este su estreno poético. Es un canto que se asienta en su propio juicio, que se sabe «enselvado» $\mathrm{y}$ «salvaje» al diseñar un paisaje simbólico con líneas duras, donde la barbarie es más un estado del alma, una ecología íntima y vibrante que tal vez será emblemática para la historia de la literatura venezolana.

En Mandato del canto, volumen con el cual obtiene el Premio Municipal de Literatura en 1957, se advierte una mayor problematización de la situación autorial, sea mediante reflexiones sobre «el canto» en general, sea apuntalando su «Voz» con la de otras voces lejanas. «Qué haré, Sara de Ibáñez, con este alterno «canto»?», ${ }^{10}$ se pregunta, apelando a la invisible red que sostiene a otras poetas en otras latitudes y contextos igualmente severos, como han demostrado fehacientemente los estudios críticos sobre redes femeninas. ${ }^{11}$

La función Autor, entendida como una relación intrínseca de los discursos con las formas de autoridad y circulación que la determinan, aparece frecuentemente aludida en sus versos de asombrosa lucidez y de una modernidad a ultranza. En particular, en el poema «Respuesta», llega a exigirle al lector virtual un signo claro, una verdad necesaria que justifique su identidad lírica desde la alteridad. ¿Cómo es esa mirada del otro? ¿Desde qué horizonte de expectativas lee mi poema? ¿Qué me entrega y qué pide a cambio? Y entonces es como un clamor desde la soledad absoluta de la creación, además de aquella social y política en

9 Enriqueta Arvelo Larriva: Voz aislada: Poemas 1930-1939. Caracas: Elite 1939, p. 60, 69, 76. 10 Enriqueta Arvelo Larriva: Mandato del canto: Poemas 1944-1946. Caracas: Cuadernos de la Asociación de Escritores Venezolanos 1962, p. 113.

11 En el contexto de la modernidad periférica, la crítica ha observado un comportamiento particular de las escritoras durante las primeras décadas del siglo. Desde espacios distantes, ellas establecieron conexiones intelectuales mediante cartas, lecturas y/o encuentros fugaces, facilitando un diálogo con rasgos comunes para superar su situación de marginalidad. Es el «invisible college» que va transformando el aislamiento en un lugar de enunciación, como observa Ana Pizarro en El sur y los trópicos (Ana Pizarro: «El invisible college»: Mujeres escritoras en la primera mitad del siglo XX». In: El sur y los trópicos: Ensayos de cultura latinoamericana. Chile: Cuadernos de América sin nombre 2004, p. 163-176), y tal como reconfirman estudios más recientes sobre alianzas y redes femeninas (Carolina Alzate y Darcie Doll: Redes, alianzas y afinidades: Mujeres y escritura en América Latina. Bogotá: Ediciones Uniandes; Santiago: Universidad de Chile 2014). Cabe destacar que Enriqueta Arvelo Larriva escenifica directamente en el espacio del poema el vínculo «alterno» con Sara de Ibáñez (en sus cartas se refiere también a Juana de Ibarbourou), individualizándose, libre de toda identificación o fusión empática. 
la que se encuentra, desde donde se pide una comprensión y un entendimiento más profundo del poema: una «recepción crítica» avant la lettre y no una simple compenetración emotiva. Y así lo exige resueltamente:

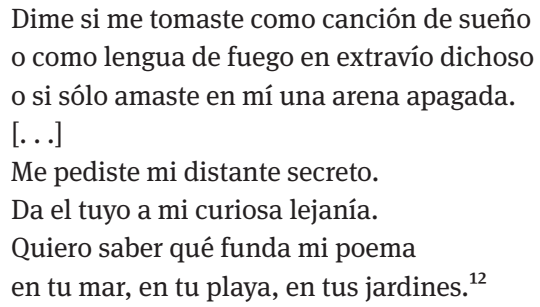

Es sorprendente comprobar cómo la construcción de la autoría, extremadamente consciente en estos poemas y en el epistolario de Enriqueta, responde a la descripción que varias décadas después haría Foucault sobre la función Autor. Como en otra danza sorjuanina, Enriqueta se revela y se camufla en la conocida carta de 1939 dirigida a su editor, Julián Padrón. Allí equilibra la precariedad social con la valentía. Desde su modestia «designorantándose» gracias a la influencia del hermano poeta, ${ }^{13}$ defiende a la vez la «evolución espontánea» e independiente de su poema (ella dice «poemita», como sor Juana hablaba de su «papelillo»). Finalmente separa al sujeto empírico del sujeto lírico cuando concluye que «la aislada no es mi voz, soy yo», ${ }^{14}$ reconociendo indirectamente la autonomía de su poesía más allá de cualquier circunstancia y condición por ella misma argumentadas. Estos son algunos de los párrafos más reveladores de la carta:

No me labré intelectualmente en ninguna parte, «designorantándome» un poquito sólo por la influencia de mi hermano, la que desde muy temprano dejó de ser inmediata, pues él dejó estos lugares siendo muy joven y cuando yo estaba en plena adolescencia. [. . .] No tengo «trayectoria». No tengo nada que se pueda anotar como de «Carrera de poetisa». [... .] Me encanta leer, pero aquí hay siempre crisis de lectura. Y leo lo que cae por mis manos porque no hay «chance» de escoger. [. . .] Pienso que cuando usted termine de leer esta carta ya me conocerá bastante. De lo que escribo, diga lo que sea indispensable nada más. Dígalo con ese modo suyo, simple y sólido. Si es posible no cite ninguna de mis frases. ${ }^{15}$

12 Enriqueta Arvelo Larriva: Mandato, p. 116-117.

13 Alfredo Arvelo Larriva (1883-1934) fue un famoso poeta modernista, apreciado en Venezuela tanto por sus rimas como por su frontal oposición a la dictadura de Juan Vicente Gómez. Fue encarcelado durante ocho años en las atroces prisiones de La Rotunda. Según opinión unánime de la crítica, la poesía de su hermana Enriqueta trasciende con creces su legado poético.

14 Enriqueta Arvelo Larriva: Prosa (Selección), tomo II. Barinas: Fundación Cultural Barinas 1987, p. 179-183.

15 La carta a Julián Padrón está incluida en Enriqueta Arvelo Larriva: Prosa, tomo II, p. 179-183. 
La carta es un extraordinario diseño de autorización y desautorización de su propia imagen, indicando al editor lo que puede decir y lo que debe callar. Incluida también en la primera página de Voz aislada, constituye una obligada presentación pública ciertamente, pero es sobre todo una guía interpretativa gobernada por la misma poeta esbozando las líneas de su poética y de cómo debe ser leída.

Y así mismo ha perdurado en la sensibilidad de muchos de sus lectores. Su lucidez sobre su condición marginal en lo cultural y geográfico, su determinación contra cualquier concesión sentimental, su extrema libertad al enfocar el paisaje venezolano con visión proto-ecológica, y la obediencia estoica al llamado profundo de la poesía como un destino, la convierten en una figura casi épica y resistente que imprime la marca indeleble de lo bárbaro y «salvaje» en la modernidad venezolana. Ese es su «mandato» sobre «lo salvaje», cuya cifra es preciso labrar - es la misma «molicie» y el «desorden» aborrecidos por Luz Machado-y que tendrá para las generaciones futuras la fuerza de un derecho político además de poético. Es un llamado asumido desde el territorio árido de las provincias, al margen de aquellas «marginalidades incomparables» ${ }^{16}$ condenadas a forjar su propia liberación. Con la obra de Enriqueta, no solamente nace la mujer artista consciente de su valor, nace también una visión bárbara de la modernidad y el rechazo a cualquier instrumentación de la poesía cual marcas de identidad y de destino que atravesarán la poesía del siglo XX venezolano.

La segunda mitad del siglo vive las primeras aperturas sociales y políticas y el despliegue de la actividad femenina en todos los sectores. Como señala una crónica de Elisa Lerner:

En Venezuela la muerte del General Gómez, no habrá de ser importante sólo para la jerarquización de una primera emoción democrática, que poco tiempo después habría de dar paso a las organizaciones políticas y sindicales: a un país menos melancólico, mucho más libre y moderno. Empezará, también, el período aural para que la mujer venezolana comience a tener destino propio, domicilio en el mundo. ${ }^{17}$

En 1940 se celebra el Primer Congreso Venezolano de la Mujer con la masiva participación de escritoras, artistas, periodistas y trabajadoras de la cultura. La lucha se centra en el derecho al voto y en importantes cambios legales y jurídicos. El sufragio femenino se obtiene tardíamente, estipulado en la primera Constitución Democrática de Venezuela en 1947, casi a mitad del siglo XX. Son años

16 Yolanda Pantin y Ana Teresa Torres: El hilo de la voz: Antología crítica de escritoras venezolanas del siglo XX. Caracas: Fundación Polar 2003.

17 Elisa Lerner: Crónicas ginecológicas. Caracas: Línea Editores 1984, p. 183. 
cruciales también para la narrativa femenina que va abriéndose paso en revistas y antologías.

En la poesía, se va generando la reflexión meta-poética como una constante, y un recurso instrumental tan variado que a veces resulta desafiante por la amplitud de sus alegorías e implicaciones. Podría afirmarse que de todos los roles del sujeto lírico estudiados por Slawinski, el rol de creador, o bien «la actitud del 〈yo〉 hacia el sujeto de los actos creadores y hacia la situación socioliteraria en que ese sujeto se halla» ${ }^{18}$ es replanteado una y otra vez con diferente intensidad y funciones.

En este sentido, resulta insuficiente una lectura reactiva o destructiva de los prejuicios y lugares comunes atribuidos a la lírica de autoría femenina, ya que el proceso meta-poético es más complejo y las diferentes figuraciones del sujeto lírico aportan aspectos inéditos en lo formal y en lo semántico.

\section{Otras poéticas, otras vanguardias}

Para explorar esta complejidad conviene concentrarnos en tres grandes figuras históricas, consideradas las «madres» de la poesía venezolana contemporáneas entre sí, Ana Enriqueta Terán (1918-2017), Ida Gramcko (1924-1994) y Elizabeth Schön (1921-2007). Sus propuestas poéticas marcan con fuerza las etapas fundantes de este itinerario desde los años 40 y hasta hoy en pos de una investigación libre de lastres retóricos del pasado y centrada en la experiencia del sujeto femenino.

Contrariamente a las tendencias de disolución del sujeto lírico, evaporado o convertido en un ser de papel, en estas poetas hallamos una conciencia celebratoria del poder de la poesía en todas sus instancias. El conocido poema meta-poético de Ana Enriqueta «Piedra de habla» constituye una poderosa demostración en este sentido, y con una contundencia, justamente, de «piedra»:

La poetisa cumple medida y riesgo de la piedra de habla.

Se comporta como a través de otras edades de otros litigios.

Ausculta el día y sólo descubre la noche en el plumaje del otoño.

Irrumpe en la sala de las congregaciones vestida del más simple acto.

Se arrodilla con sus riquezas en la madriguera de la iguana.

18 Janusz Slawinski: «Sobre la categoría del sujeto lírico». In: Textos y contextos, tomo II. La Habana: Arte y Literatura 1989, p. 240. 
Una vez todo listo regresa al lugar de origen. Lugar de improperios. Se niegan sus aves sagradas, su cueva con poca luz, modo y rareza. Cobardía y extraño arrojo frente a la edad y sus puntos de oro macizo. La poetisa responde de cada fuego, de toda quimera, entrecejo, altura que se repite en igual tristeza, en igual forcejeo por más sombra por una poquita de más dulzura para el envejecido rango.

La poetisa ofrece sus águilas. Resplandece en sus aves de nube profunda. Se hace dueña de las estaciones, las cuatro perras del buen y mal tiempo. Se hace dueña de rocallas y peladeros escogidos con toda intención. Clava una guacamaya donde ha de arrodillarse.

La poetisa cumple medida y riesgo de la piedra de habla. ${ }^{19}$

Hay aquí una representación/consagración de la figura del poeta, enfáticamente subrayada en femenino e indiferente a la devaluación que ha sufrido el término «poetisa» a través del tiempo. Aunque no se trata de realizar un análisis detallado de este fascinante texto, quedan claramente evidenciados sus mayores indicios: orgullo y afirmación de la genealogía, exaltación identitaria de género, y también de linaje considerando el rancio abolengo de la autora como descendiente de antiguos hacendados establecidos en el estado Trujillo, desde la Colonia. Prueba convincente del dominio del ejercicio/oficio poético mediante un amplio registro compositivo, que ella pasa libremente de metáforas surrealistas («aves de nube profunda») a la felicidad prosaica de los términos locales («iguana», «guacamaya», «peladeros»), hasta la realización «de toda quimera».

El sujeto lírico parece expresar la conciencia de un poder que le pertenece intrínsecamente: es suya la palabra poética y su capacidad de organización intelectual y representacional, en la realidad y en el mito. La enunciación y el enunciado se corresponden y se manifiestan en numerosas formas de acción y posesión (cumplir, comportarse, auscultar, irrumpir, regresar, responder, ofrecer, adueñarse, clavar, entre otros). Como si dijera «la poesía es mía», ella es pensamiento y acción, lenguaje que no traiciona. Aunque el sujeto lírico es el centro de la experiencia, la singularidad de dicha experiencia -que es existencial e intelectual a la vez - «arrastra» el poema hacia la materialidad del lenguaje, conjugando dos poéticas de raíces distintas en una misma autora, y en un mismo poema: una, de raíz clásica, y otra experimental.

En el caso de Ida Gramcko, las diferentes facetas de su obra revelan una conciencia crítica y autorreflexiva, si es posible, más radical. La palabra adquiere una capacidad mágica y generadora de mundos: es el verbum del origen que se desata como cascada en torrenciales sonetos de perfección formal. La palabra del

19 Ana Enriqueta Terán: El libro de los oficios. Caracas: Monte Ávila 1975, p. 15. 
poeta es equivalente al Verbum Domini, de procedencia divina, incontaminada y pura en su hacer brotar las cosas de la nada. Y es en este mismo sentido que ella es interpelada mediante la prosopopeya y el llamado en segunda persona:

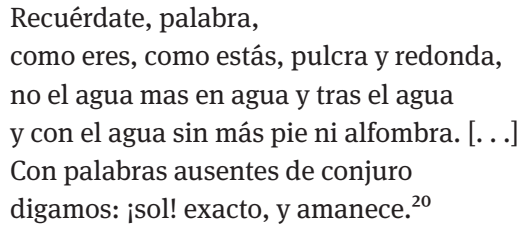

Pero lo sagrado y lo profano enfrentados en una poética de dimensión cósmica terminan por fagocitar al sujeto lírico. No hay otro evento en la poesía de Ida sobre todo a partir de los años 60- que esta potencia arrolladora de orfismo encantatorio; ningún verso, anécdota o escena que permita un resquicio de compañía y cotidianidad junto al calor humano. Toda referencialidad se remite circularmente a la fabulación, a lo arquetípico y al misterio indescifrable de la creación sin otras mediaciones, como si el mundo y la vida real de todos los días hubieran quedado entre paréntesis, o entre «puras y primigenias pulsaciones». ${ }^{21}$ En esta caída abismal bajo el dominio asfixiante del delirio poético, el sujeto lírico, ahora desgajado de sus «adherencias» históricas y psico-sociales, no es más que un vasallo devorado por su propio canto.

La biografía de Ida realizada por Gabriela Kizer recoge puntualmente el proceso de la crisis psicótica que aquejó a la precoz y talentosa poeta, y cuyo testimonio aparece en Poemas de una psicótica (1964). Fue una grave suplantación de la vida por un poder visionario incontrolable. Como afirma Alfredo Chacón:

\begin{abstract}
Ida tenía una confianza absoluta en ese poderío espiritual que la hacía hablar, en su capacidad volcánica para dar al mundo poesía. Ella se vivió a sí misma como una fuerza de la poesía, de la naturaleza poética. Eso, creo yo, originó a un ser humano para el cual la vida se volvió puramente metafórica - un metaforismo que podríamos llamar prometéico. ${ }^{22}$
\end{abstract}

Aunque este triste desenlace no podría ofuscar la magnitud creadora de la poeta en los diferentes géneros que cultivó, incluso como ensayista, dramaturga y una de las primeras articulista y reportera del diario El Nacional donde registró con agudeza e ironía aspectos de la vida cultural de su tiempo, el mismo revela los

20 Ida Gramcko: Poemas. México: Editorial Atlante 1952, p. 64-65.

21 Ida Gramcko: Salto Ángel. Caracas: Fundarte 1985, p. 39.

22 Alfredo Chacón citado in: Gabriela Kizer: Ida Gramcko. Caracas: C.A. Editora El Nacional. Biblioteca Biográfica Venezolana, vol. 125, 2010, p. 88. 
efectos desestructurantes de una metapoética llevada al extremo, en un contexto de modernidad periférica que «atañe sobre todo al sujeto que la experimenta». ${ }^{23}$

Por su parte, Elizabeth Schön continúa escalando la consagración del género «mayor», también a través del poema en prosa y en términos cada vez más abstractos, enfatizando la fuerza de la palabra como medio para la evocación y para la aparición epifánica:

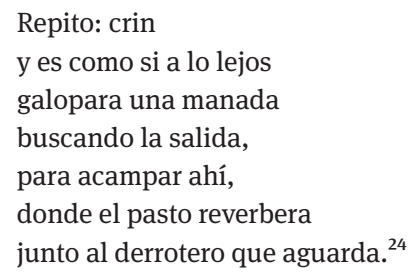

Estudiosa de las ciencias del lenguaje desde los presocráticos y la mística española, desarrolla los temas propios de este género, el milagro de la coexistencia entre el vacío y la palabra, ya que «la palabra es la casa del ser». En un largo ensayo poético de corte intergenérico, donde mezcla versos y prosa poética, expone las bases de su complejo universo metafísico. Para ello se apoya tanto en el pensamiento de sus maestros -Heidegger, Lao Tse, entre otros- como en definiciones literarias a través de fragmentos alegóricos: «La palabra del poeta alumbra el propio árbol pronunciado» - dice. Y luego hace una descripción metafórica de la metáfora (valga la redundancia) que constituye en sí un giro poético completo y autosuficiente: «La metáfora se forma por la necesidad inexorable de originar un «canto〉 al que le fue dado contener una raíz y conducirla hasta la cumbre». ${ }^{25}$

Poesía de la poesía, poesía en segundo grado, meta-poética, creación elevada a la máxima potencia, teoría ontológica del lenguaje, como quiera que se les quiera llamar, se trata de propuestas problematizadoras de la modernidad literaria que establecen una serie de tensiones controversiales: entre lenguaje poético y lenguaje teórico, entre formas clásicas y experimentales, y entre discursos paralelos que problematizan la relación autor-texto-público comprometiendo la identidad misma del sujeto lírico en primer plano. Como recuerda Adorno, la exaltación del sujeto lírico o su anulación en el lenguaje constituye el aspecto más revelador y consustancial de la lírica en su relación con la sociedad. Por lo cual -advierte-:

23 Saúl Yurkievich: La movediza modernidad. Madrid: Taurus 1996, p. 11.

24 Elizabeth Schön: La cisterna insondable. Caracas: Consejo Municipal del Distrito Federal 1971, p. 101.

25 Elizabeth Schön: La Casa Bella de la Granja. Caracas: Eclepsidra 2003, p. 48. 
[...] el instante del autoolvido, en el cual el sujeto se sumerge en el lenguaje, no es el sacrificio del sujeto al ser. No es un instante de violencia, no de violencia contra el sujeto, sino un instante de reconciliación: la lengua no habla sino cuando deja de hablar como algo ajeno al sujeto y habla como voz propia de este. Cuando el 〈yo〉 se olvida en el lenguaje está del todo presente en él. ${ }^{26}$

En este sentido, y propiciados por la larga vida y productividad de estas poetas consideradas con justicia «fundacionales», elementos de vanguardia se atraviesan como relámpagos sobre la superficie tersa de los versos, mientras función y sustancia de la expresión más arcana - la oralidad, el canto, el sentir comunitario- resisten al avance de nuevos conflictos y visiones de mundo.

Se podría concluir que en el «puente de dos manos» de la vanguardia identificado por los críticos latinoamericanos. ${ }^{27}$ las poetas venezolanas del siglo XX transitaron una tercera vía, equidistante tanto del polo de religación interna como del externo. Sus propuestas parecen trascender la escisión entre la visión que valora los elementos internos y locales de la propia cultura (polo transculturado) y la que responde tan solo a la compulsión internacional de las grandes transformaciones mundiales (polo cosmopolita). Pensamos que el lugar que ellas ocupan en la historia literaria, según el acertado concepto de vanguardia «doble», no puede considerarse estable ni representativo de ningún polo ya que, si por una parte se modernizan sin perder los elementos de la tradición local superando «los equívocos del dualismo modernidad/tradición», ${ }^{28}$ por la otra se disponen a explorar otras formas y saberes, otras dimensiones de la «actualidad» de su tiempo y del más remoto pasado con una libertad y propósitos inéditos. Reconfigurando la distancia entre lo interno y lo externo, lo propio y lo ajeno, revirtieron visiones anquilosadas del arte poética, y muchas veces desafiaron la mentalidad de su tiempo que pretendía pre-asignarles un programa ajeno. Inventaron así su propia vanguardia, según su ritmo vital y las «adherencias» históricas y sociales de su género.

\section{Nuevas epifanías o ninguna}

La pregunta por la naturaleza de la poesía y sus implicaciones desde la enunciación femenina es una constante que atraviesa las convulsiones de un siglo de enorme complejidad sociopolítica que no puede resumirse en pocas páginas.

26 Theodor W. Adorno: Notas de literatura. Barcelona: Ariel 1962, p. 61.

27 En el marco de la crítica latinoamericana de tendencia culturalista, cabe mencionar a Ángel Rama, Jorge Schwartz y Alfredo Bosi, entre otros.

28 Ángel Rama: Transculturación narrativa en América Latina. México: Siglo XXI 1982, p. 72. 
Nos hemos detenido en los momentos de mayor significación porque constituyen la base de una tradición estructurándose y, en cierto sentido, un mensaje simbólico de resistencia ante el colapso de un país. Son los momentos que aportan una lúcida problematización de los valores en juego, tanto para la poesía como para la sociedad, lo cual es preciso considerar a la hora de completar el perfil de nuestra cultura. Ante la grave crisis sociopolítica, ética y moral que atraviesa Venezuela desde finales de siglo y hasta hoy, y ante la pérdida de capital humano que representa el éxodo masivo de venezolanos fuera de sus fronteras en condiciones infrahumanas, cabe preguntarse: ¿qué viene ahora? ¿Sabremos honrar la herencia que nos dejaron las fundadoras? ¿Qué nuevos retos enfrenta la poesía en nuestra cercana contemporaneidad?

Antonio López Ortega hace un diagnóstico implacable sobre la pérdida de conquistas consagradas que animaron el clima cultural efervescente de las décadas de los 70 y 80 . Fueron años marcados por el debate y la polémica intelectual, las revistas de vanguardia, las exposiciones de arte y los manifiestos aguerridos reinventando el sentido de la literatura. Si su desaparición cumple con el designio fatal de todas las vanguardias, ya que toda vanguardia desarticula la tradición para terminar fatalmente absorbida por ella, el resultado tiene como consecuencia un nuevo tipo de soledad: «Con la muerte de los grupos, las ideas o cosmovisiones literarias dejan de tener voz colectiva y ahora se pronuncian, si acaso, al unísono. Se extingue la voz de la tribu y sólo queda el susurro de las voces solitarias». ${ }^{29}$

Los talleres literarios en particular, creados en los años 70 por el Centro de Estudios Latinoamericanos Rómulo Gallegos (CELARG) con la colaboración de reconocidos escritores latinoamericanos exiliados, fueron un semillero y un espacio seguro para la participación femenina, ya que permitieron el contacto en vivo con autores consagrados y un modo de autorizar tímidamente la propia escritura. Fue una labor paralela a la de las universidades durante el proceso de renovación académica, lo cual generó una amplia producción poética de mujeres ilustradas que escriben, traducen, viajan, dictan cátedra y viven la teoría y la lectura de todos los libros como una unidad indisoluble del proceso de escritura. Se trata de un corpus específico que todavía espera por un estudio comprensivo, que también debería incluir la extraordinaria labor editorial que emprendieron algunas poetas al crear pequeñas casas editoras de exquisita calidad en forma y contenido, dedicadas a la poesía exclusivamente, como Pequeña Venecia en

29 Antonio López Ortega: «El fin de las cofradías: grupos literarios en la Venezuela de los 80». In: Cuadernos Hispanoamericanos 748 (2012), p. 63. 
1989, Eclepsidra en 1994 y el Taller Editorial el Pez Soluble en 1998, entre otras, todavía hoy activas a pesar de las crisis y todo tipo de restricciones. ${ }^{30}$

Como vimos, las poetas venezolanas se mantuvieron siempre un poco ajenas a poéticas colectivas, cumpliendo en cambio según su «medida y riesgo», como afirma el verso de Ana Enriqueta Terán, con poéticas individuales o «poética de poetas», tendencia esta que parece imponerse y que nos lleva a reinterpretar incesantemente la historia literaria. Fueron por eso modernas y contemporáneas, anacrónicas y actuales, aisladas y a la vez sostenidas por su propia vocación y por el diálogo a través de cartas y lecturas compartidas con sus congéneres.

Pero este mapa esquivo y envuelto en las tinieblas no podrá decir la última palabra. Enunciado desde otra perspectiva, la afirmación de Yurkievich podría replantearlo: «El arte y la literatura, como la historia que nos incluye y condiciona, son oscilantes en su progresión sin progreso». ${ }^{31}$ ¿Quiere decir esto que la poesía no morirá? ¿Se apagará aquella pequeña lámpara gemela arrasada por los bárbaros? ¿Sabremos «cifrar lo salvaje» que nos constituye como individuos y como civilización?

Solo el tiempo lo dirá, si acaso queda tiempo. Solo otras epifanías.

\section{Bibliografía}

Adorno, Theodor W.: Notas de literatura. Barcelona: Ariel 1962.

Alzate, Carolina y Darcie Doll (eds.): Redes, alianzas y afinidades: Mujeres y escritura en América Latina. Bogotá: Ediciones Uniandes; Santiago: Universidad de Chile 2014.

Arvelo Larriva, Enriqueta: Voz aislada: Poemas 1930-1939. Caracas: Elite 1939.

-: Prosa (Selección), tomo II, investig., selec., compil., pról. y notas de Carmen Mannarino. Barinas: Fundación Cultural Barinas 1987.

-: Mandato del canto: Poemas 1944-1946. Caracas: Cuadernos de la Asociación de Escritores Venezolanos 1962.

Bosi, Alfredo: «La parábola de las vanguardias latinoamericanas». In: Jorge Schwartz: Las vanguardias latinoamericanas, textos programáticos y críticos. Madrid: Cátedra 1991.

Combe, Dominique: «A referência desdobrada: 0 sujeito lírico entre a ficção e a autobiografia». In: Revista USP 84 (2010), p. 113-128.

Cruz, Sor Juana Inés de la: «Respuesta de la poetisa a la muy ilustre sor Filotea de la Cruz». In: Obra selecta, vol. II, p. 450-491. Caracas: Biblioteca Ayacucho 1994.

Foucault, Michel: «Qué es un autor». In: Literatura y conocimiento. Mérida: Universidad de los Andes 1999.

30 Cabe nombrar a Blanca Elena Pantin, Yolanda Pantin, Carmen Verde, Belkis Arredondo, entre otras.

31 Saúl Yurkievich: La movediza, p. 337. 
Gallegos, Rómulo: Doña Bárbara. México: FCE 1954.

Gramcko, Ida: Poemas. México: Editorial Atlante 1952.

-: Poemas de una psicótica. Caracas: Grafos 1964.

-: Salto Ángel. Caracas: Fundarte 1985.

González, Patricia Elena y Ortega, Eliana (eds.): La sartén por el mango. Encuentro de escritoras latinoamericanas. San Juan [Puerto Rico]: Huracán 1984.

Horacio: Arte poética y otros poemas, trad. y notas de Óscar Gerardo Ramos. Bogotá: Instituto Caro y Cuervo 1974.

Kizer, Gabriela: Ida Gramcko. Caracas: C.A. Editora El Nacional. Biblioteca biográfica venezolana, vol. 125, 2010.

Lerner, Elisa: Crónicas ginecológicas. Caracas: Línea Editores 1984.

Antonio López Ortega: «El fin de las cofradías: grupos literarios en la Venezuela de los 80». In: Cuadernos Hispanoamericanos 748 (2012), p. 57-64. http://www.cervantesvirtual.com/ descargaPdf/el-fin-de-las-cofradias-grupos-literarios-en-la-venezuela-de-los-80-877624/ [Consultado el 11 de diciembre 2019].

Machado, Luz: Sonetos a la sombra de sor Juana Inés de la Cruz. Caracas: Ediciones Poesía de Venezuela 1966.

-: La casa por dentro (1964-1965). Caracas: Sucre 1965.

Miranda, Julio: Poesía en el Espejo: Estudio y Antología de la nueva lírica femenina venezolana, 1970-1994. Caracas: Fundarte 1995.

Pantin, Yolanda y Ana Teresa Torres: El hilo de la voz: Antología crítica de escritoras venezolanas del siglo XX. Caracas: Fundación Polar 2003.

Pizarro, Ana: «El «invisible college»: Mujeres escritoras en la primera mitad del siglo XX». In: El sur y los trópicos: Ensayos de cultura latinoamericana. Chile: Cuadernos de América sin nombre 2004.

Rama, Ángel: Transculturación narrativa en América Latina. México: Siglo XXI 1982.

Russotto, Márgara: Bárbaras e ilustradas. Las máscaras del género en la periferia moderna. Caracas: Fondo Editorial Tropykos 1997.

Schön, Elizabeth: La Casa Bella de la Granja. Caracas: Eclepsidra 2003.

-: La cisterna insondable. Caracas: Consejo Municipal del Distrito Federal 1971.

Schwartz, Jorge: Las vanguardias latinoamericanas, textos programáticos y críticos. Madrid: Cátedra 1991.

Slawinski, Janusz: «Sobre la categoría del sujeto lírico». In: Textos y contextos, tomo II, selec. de Desiderio Navarro. La Habana: Arte y Literatura 1989.

Terán, Ana Enriqueta: El libro de los oficios. Caracas: Monte Ávila 1975.

-: Piedra de habla. Caracas: Fundación Biblioteca Ayacucho 2014.

Traba, Marta: «La literatura femenina». El Universal (25 de enero de 1981). Caracas.

Yurkievich, Saúl: La movediza modernidad. Madrid: Taurus 1996. 